\title{
AUTONOMIA, LIBERDADE E MORALIDADE NA FILOSOFIA PRÁTICA KANTIANA $^{1}$
}

\section{AUTONOMY, FREEDOM, AND MORALITY IN KANT'S PRACTICAL PHILOSOPHY}

\begin{abstract}
RESUMO
Este artigo expõe a centralidade da noção de liberdade na relação entre imperativo categórico e autonomia da vontade na filosofia moral kantiana. Após a introdução, que apresenta o problema da primazia entre formulações do imperativo categórico (formulação canônica e formulação da autonomia), o artigo divide-se em duas partes. Em primeiro lugar, exploramos a relação entre imperativo categórico e autonomia através da discussão das interpretações de Bernard Carnois e Henry Allison, recusando a proposta de uma autonomia não moral. Em segundo lugar, expomos, em linhas gerais, os problemas que se seguem dessa relação conforme a terceira seção da Fundamentação, centrando nossa análise na noção de liberdade positiva e nas dificuldades derivadas da noção de dedução.
\end{abstract}

Palavras-chave: Imperativo. Autonomia. Liberdade. Fundamentação.

\begin{abstract}
ABSCTRACT
This article exposes the centrality of the notion of freedom in the relation between categorical imperative and autonomy of will in Kant's practical philosophy. After the introduction, which presents the problem of the primacy among formulations of the categorical imperative (canonical formulation and formulation of the autonomy), the article is divided in two parts. In the first part, I examined the relation between categorical imperative and autonomy through the discussion on the interpretations of Bernard Carnois and Henry Allison, subsequently refusing the proposal of a 'no moral autonomy'. In the second part, I exposed the problems of that relation in Groundwork III, centering my analysis on the concept of positive freedom and the derived difficulties of the notion of deduction.
\end{abstract}

Keywords: Imperative. Autonomy. Freedom. Groundwork.

\footnotetext{
${ }^{1}$ Artigo originado de pesquisa financiada pela FAPESP (Proc.: 2016/06170-3).

${ }^{2}$ Mestrando em Filosofia pela Universidade de São Paulo (USP).

CV Lattes: http://lattes.cnpq.br/5434175861244059.

ORCID: https://orcid.org/0000-0003-2805-2737.
} 


\section{INTRODUÇÃO}

É dito na Fundamentação da metafísica dos $\operatorname{costumes}^{3}$ que as diversas formulações do imperativo categórico são modos de representar a mesma lei e que cada uma contém em si todas as outras. Ainda assim, há duas razões para serem apresentadas essas formulações: explicitar o conteúdo do conceito de imperativo categórico e aproximá-lo o mais possível da intuição empírica. A primeira razão pode ser chamada objetivo-conceitual; a segunda, subjetivo-prática. No entanto, ainda que exista a função de aproximar o conteúdo abstrato do imperativo à experiência, "no ajuizamento moral, é melhor proceder sempre segundo o método rigoroso, tomando por base a fórmula universal do imperativo categórico: age segundo a máxima que possa sempre fazer de si mesma uma lei universal" (GMS, AA IV: 436; p. 273). A primeira formulação do imperativo categórico, comumente chamada de formulação canônica, figura assim como o modelo privilegiado em relação às demais.

Contudo, esse aparente privilégio da primeira formulação torna-se fraco no decorrer do texto. Reservando à última seção da obra a prova da validade objetiva do imperativo categórico, bem como a prova de que a autonomia da vontade deve ser um princípio ao qual a vontade de todo ser racional está necessariamente ligada, Kant ressalta um aspecto importante da autonomia

Todavia, que o mencionado princípio [a autonomia da vontade] seja o único princípio da moralidade, [é algo que] se pode muito bem mostrar por mera análise dos conceitos de moralidade. Pois, desse modo, descobre-se que seu princípio tem de ser um imperativo categórico; este, porém comanda nada mais, nada menos do que precisamente essa autonomia. (GMS, AA IV: 400; p. 287)

Desse modo, a autonomia se apresenta como central, sendo o imperativo categórico (formulação canônica) quase que subsidiário: a autonomia figura agora como princípio supremo da moralidade. Será dessa confusão textual entre os papeis central e subsidiário que surgirá, na tradição de leitores da filosofia moral kantiana, uma série de dificuldades consideráveis acerca da relação entre os dois conceitos e as duas formulações. Afinal, qual das duas formulações do imperativo categórico, a canônica ou a da autonomia, deve receber primazia por parte do intérprete?

\footnotetext{
${ }^{3}$ As citações de Kant serão feitas no corpo do texto com, respectivamente, sigla da obra, numeração na edição da Academia e página, seguidos da paginação da tradução em língua portuguesa. As citações da Crítica da razão pura seguem no corpo do texto segundo as edições de 1781 (A) e 1787 (B). As traduções utilizadas se encontram na bibliografia.
} 
Há uma dupla ordem de dificuldades que cercam a relação entre os conceitos de autonomia e imperativo categórico. A primeira ordem de dificuldades é fundamentalmente baseada nesse problema da primazia e apresentada por Bernard Carnois (1973, p. 84) como a conciliação entre a primazia da autonomia e a do imperativo categórico no que diz respeito à ação moral. A segunda ordem de dificuldades também se baseia, a nosso ver, nessa aparente dualidade, somada à multiplicidade das concepções de autonomia e, conforme apresentada por Henry Allison (1995, p. 94-95), é composta por problemas que cercam a concepção moral kantiana enquanto uma moral da autonomia: a autonomia é exposta tanto como uma propriedade da vontade de todo ser racional quanto como o princípio supremo da moral e, na medida em que é o princípio supremo, a autonomia da vontade faz as vezes tanto de uma das formulações do imperativo categórico quanto de sua condição de possibilidade.

As duas ordens de dificuldades baseiam-se em problemas textuais da Fundamentação. Supondo-se que não se trata de problemas gráficos ou de uma confusão terminológica por parte do autor, mas antes de dificuldades filosoficamente relevantes e vinculadas à compreensão da filosofia moral kantiana, buscamos circunscrever o núcleo filosófico do problema sem depender de fatores externos para sua interpretação. ${ }^{4} \mathrm{Na}$ primeira parte do artigo, apresentamos as posições dos comentadores Bernard Carnois e Henry Allison e fazemos uma avaliação crítica de ambos. ${ }^{5}$ Nosso objetivo é defender a tese segundo a qual a

\footnotetext{
${ }^{4}$ De passagem, deve-se ressaltar como pressuposto deste trabalho a recusa de toda intepretação historicista ou psicologista dos conceitos que articulam o discurso filosófico kantiano, e de modo particular do conceito de autonomia. No que diz respeito à interpretação psicologista, como observa Thomas E. Hill Jr. (1992, p. 77-78), constantemente o termo "autonomia" é usado em sentido psicológico, como expressão de certa maturidade por parte do sujeito. Ora, entre essa noção psicológica de autonomia e a ideia propriamente kantiana há diferenças que, como observa o comentador, precisam ser consideradas. A principal diferença está no fato de que a noção psicológica de autonomia está baseada em um discernimento empírico das ações do sujeito, podendo ser atribuída em vários graus e sentidos, ao passo que a noção kantiana de autonomia é sempre exposta como produção, não da experiência empírica, mas sim da razão, fundamentada a priori na vontade de todo ser racional. No que diz respeito à leitura historicista, Roger J. Sullivan é um exemplo paradigmático. Em sua análise da formulação da autonomia, Sullivan argumenta que Kant, “[...] vivendo em uma sociedade pré-darwiniana e de certa homogeneidade cristã [...], parece não ter tido consciência de que há certos problemas no uso da noção de 'fins naturais' em um tipo de moral constitutiva" (SULLIVAN, 2000, p. 190-191). Para o comentador, o problema estaria no fato de Kant não ter percebido que os fins naturais não se conciliariam facilmente com sua moralidade racionalmente constituída e que, ao fundamentar a moralidade em certos fins naturais, o filósofo estaria simplesmente respondendo ou seguindo certa tendência de sua época, que não poderia compatibilizar-se com a noção de autonomia. Contra essa interpretação, insistimos no caráter racional da investigação da autonomia, que, fundada na análise do conhecimento racional moral comum, isto é, da capacidade judicativa aplicada ao campo prático e em nível pré-filosófico, sempre se estabeleceu em marcos racionais, não históricos. Daí não se segue, contudo, uma recusa a qualquer interpretação histórica da filosofia kantiana. Por exemplo, J. B. Schneewind (2005, p. 29-32), aos expor os aspectos considerados inovadores na concepção kantiana de autonomia, ressalta que esse conceito foi, de certo modo, inventado pelo filósofo e representa o ponto de chegada de um desenvolvimento histórico que, aos poucos, dá ao sujeito a autoridade e legitimidade para a autolegislação moral, não cabendo mais, portanto, nem à tradição histórica nem à vontade divina essa função.

${ }^{5}$ Há, entre as duas leituras de Kant, uma série de paralelos impressionantes aos quais deveríamos nos atentar; porém, dada a natureza do artigo, não é possível fazê-lo em detalhes. Ainda assim, gostaríamos de frisar alguns deles, que, a nosso ver, são relevantes para a defesa do paralelo que construiremos no decorrer do texto. Ambo
} 
dificuldade apresentada não constitui um problema para a moral kantiana, mas antes um de seus desdobramentos mais originais no que diz respeito ao afastamento de toda heteronomia da moralidade, centrada na identidade entre autonomia e liberdade. Na segunda parte do artigo, apontamos alguns aspectos de um problema que, como pretendemos expor, conecta-se com o problema anterior: compreender como é possível a liberdade da vontade (idêntica à autonomia da vontade) sob condições humanas. Preocupamo-nos, especialmente, com estabelecer os contornos filosóficos desse problema clássico e sua relação, nem sempre clara, com a questão da primazia das formulações umas em relação às outras, na esperança de contribuirmos para a circunscrição das questões filosóficas concernentes.

\section{A RELAÇÃO ENTRE IMPERATIVO CATEGÓRICO E AUTONOMIA DA VONTADE: AS INTERPRETAÇÕES DE BERNARD CARNOIS E HENRY ALLISON}

Bernard Carnois possui uma interpretação ampla da concepção kantiana de autonomia, que deve ser apresentada para que consigamos compreender sua leitura do problema. Para Carnois (1973, p. 79-80), a concepção kantiana de autonomia surge no interior do sistema crítico como fruto de uma longa maturação das ideias, não como iluminação repentina - uma busca, por parte do filósofo, de uma concepção equilibrada de moralidade. Somente assim pode-se compreender o fato de a autonomia estar ausente na primeira Crítica e só ser apresentada na Fundamentação após as longas análises dos conceitos de boa vontade, dever, respeito e imperativo categórico. A autonomia é fruto da atividade filosófica em seu desenvolvimento conceitual, produzida a partir da análise do imperativo categórico e prosseguindo, ainda, pelos conceitos de liberdade positiva e negativa, pelo facto da razão, chegando, finalmente, ao conceito de mal radical. Assim, o comentador divide em três aspectos a relação entre imperativo categórico e autonomia da vontade: (i) a autonomia da vontade aparece, em primeiro lugar, como condição de possibilidade lógica do imperativo categórico; (ii) o imperativo categórico também requer, como condição de sua possibilidade

os comentadores defendem como núcleo fundamental da investigação o lugar privilegiado da ideia de liberdade no interior da filosofia moral kantiana, tanto no que diz respeito à filosofia teórica e ainda mais no que diz respeito à filosofia prática (CARNOIS, 1973, p. 11-13; ALLISON, 1995 p. 1-7). Ambos iniciam suas investigações retomando a Terceira Antinomia e passando, assim, pela Fundamentação, por trechos da Crítica da razão prática e, finalmente, pela interpretação da doutrina do mal radical. Allison cita expressamente Carnois no início do livro, o que indica um parentesco significativo, ainda que com diferenças, entre as investigações de ambos. 
transcendental, a autonomia da vontade; e (iii) a realidade objetiva da autonomia da vontade é atestada pelo facto da razão. Para essa interpretação são articulados três textos distintos: a segunda e a terceira seções da Fundamentação e a Analítica Transcendental da Crítica da razão prática.

É nessa tese geral que se baseia a compreensão que Carnois tem da questão da primazia das formulações no que diz respeito ao estatuto da ação moral em Kant. Para o autor, há uma dupla primazia que opera em dois planos distintos e que justificaria a ambiguidade do texto da Fundamentação. A segunda seção da Fundamentação teria uma dupla tarefa: (i) estabelecer as regras da conduta moral; e (ii) fundamentar a própria moralidade. A primeira tarefa é executada mediante a solução dos problemas ligados à aplicação do imperativo categórico, independente de sabermos se ele existe ou não; assim, segue-se a determinação dos deveres ${ }^{6}$ que derivam do imperativo categórico como modos de orientação da ação moral: nessa perspectiva, a formulação da lei universal aparece como princípio supremo da moralidade e como critério supremo de avaliação das ações com valor moral, dado que, tendo essa formulação como irradiadora das demais, são determinadas as ações. Contudo, continua Carnois, o objetivo principal da obra é o fundamento da moralidade, que constitui a segunda tarefa

\begin{abstract}
As duas etapas são necessárias para atender o objetivo porque, como sabemos, Kant examina a questão da possibilidade lógica do imperativo categórico antes de sua possibilidade real. Entretanto, em ambos os casos a autonomia da vontade aparece como condição de possibilidade da moralidade, como "a condição suprema" (oberste Bedingung) do acordo da vontade com a razão prática universal. Deste ponto de vista, não há dúvida de que a formulação III [Formulação da Autonomia] imponha-se sobre a formulação I [Formulação Canônica] e mereça o título de "princípio supremo da moralidade". (CARNOIS, 1973, p. 84)
\end{abstract}

Nessa segunda tarefa, o intérprete fundamenta a primazia da autonomia devido a um fato crucial: ela expressaria a essência mesma do imperativo categórico (Carnois, 1973, p. 84-

\footnotetext{
${ }^{6}$ Após a apresentação da segunda formulação (formulação da lei da natureza), Kant apresenta quatro deveres, dividindo-os em deveres para conosco e para com os outros: manter a própria vida, manter uma promessa, desenvolver os talentos e ser benevolente em relação aos sofrimentos alheios (GMS, AA IV: 421; p. 215). Dada a analogia proposta entre a universalidade do princípio moral e a universalidade das leis da natureza, cada um desses deveres será fundamentado, justamente, pela expectativa de atender ou não a um grau de universalidade análogo ao das leis da natureza e rearticulado para outras formulações do imperativo categórico. Dados os objetivos deste artigo, não realizaremos uma exposição detalhada nem a discussão entre os comentadores acerca dos exemplos utilizados por Kant. Para uma exposição em detalhes, cf. ALLISON, 2011, p. 183-190; WOOD, SCHÖNECKER, 2014, p. 130-139.
} 
85). ${ }^{7}$ Assim, o conceito de imperativo categórico exigiria para sua realização, como condição lógica de sua possibilidade, a ideia de uma vontade universalmente legislante. Como vimos, Bernard Carnois concilia a dualidade do texto da Fundamentação distinguindo as duas tarefas da investigação: enquanto estabelecimento das regras de conduta, a primazia é da formulação canônica; enquanto investigação das condições de possibilidade do imperativo categórico, a primazia é da formulação da autonomia. A primazia da formulação da autonomia nesse contexto atende à primeira exigência do argumento extenso de Carnois: estabelecer a autonomia como condição lógica do imperativo categórico. Os próximos passos de sua análise serão a prova, através da leitura da terceira seção da Fundamentação, da autonomia como condição transcendental do imperativo categórico e, finalmente, da leitura da Analítica Transcendental da Crítica da razão prática para apresentar o facto da razão como a demonstração da realidade objetiva da autonomia. Voltaremos a esse tópico no decorrer do artigo ao discutirmos as diferentes leituras da relação entre a Fundamentação e a Crítica da razão prática; contudo, no que diz respeito à problemática em questão, gostaríamos de manter no horizonte de interpretação a leitura essencialista que Carnois está propondo e na qual se baseia sua compreensão do problema.

Henry Allison, ao interpretar as mesmas passagens, deriva a série dos problemas ligados ao conceito de autonomia tendo como pano de fundo a investigação da filosofia moral kantiana enquanto filosofia do agente racional. Para Allison, a concepção kantiana do agente moral inclui uma psicologia moral, desenvolvida à luz do conceito de autonomia apresentado na Fundamentação. O agente racional é caracterizado por sua capacidade de agir com base em imperativos, podendo ser estes subjetivamente válidos ou objetivamente válidos. A distinção fundamental nesse trecho é a entre máximas e leis, ou entre princípios subjetivos e objetivos da ação. ${ }^{8}$ Ora, é nesse contexto que surge a ambiguidade da concepção de

\footnotetext{
${ }^{7}$ A interpretação do comentador nesse momento se baseia na seguinte passagem da Fundamentação: "[...] Contudo, uma coisa poderia ter ocorrido, a saber, que a renúncia a todo interesse no querer por dever fosse também indicada, como nota específica (Unterscheidungszeichen) do imperativo categórico a distingui-lo do hipotético, no mesmo imperativo mediante uma determinação qualquer nele contida, e é isso o que ocorre na presente terceira fórmula do princípio, a saber, na ideia da vontade de todo ser racional enquanto vontade universalmente legislante" (GMS, AA IV: 431-432; p. 253). Carnois, utilizando a tradução francesa de Victor Delbos, (1957, p. 155-156), traduz "notas específicas" (Unterscheidungszeichen) por "caractère spécifique".

${ }^{8}$ Subjacente à análise de Allison está a discussão acerca da relação e caracterização dos conceitos de lei e máximas empreendida por L. W. Beck (1960, p. 180) e H. J. Paton (1971, p. 136-137). Em linhas gerais, deve-se recordar que, segundo Kant, a representação da lei (GMS, AA IV: 401; p. 129-131), que só tem lugar no ser racional, aparece como fundamento determinante da vontade. Se essa representação só tem lugar no ser racional e, ao mesmo tempo, tem influência sobre a vontade, percebe-se como a razão, enquanto razão prática, garante a realização da boa vontade em sua função de determinação. A razão prática determinaria plenamente a vontade a partir de uma princípio puramente formal se não houvesse a influência das inclinações que interferem nessa determinação (GMS, AA IV: 404-401; p. 129); daí que, para o ente racional finito, a boa vontade - fruto da determinação da razão prática sobre a vontade a partir da representação da lei - se apresenta como devet
} 
autonomia, em que ela, como expomos anteriormente, é apresentada por Kant como propriedade da vontade e como princípio moral e, enquanto princípio moral, ela é uma formulação do imperativo categórico e a condição de possibilidade do próprio imperativo. Para a solução dessa dificuldade, Allison propõe um duplo tratamento da questão: (i) primeiro devemos tratar a autonomia como propriedade da vontade, sendo que essa análise opera como base para (ii) a compreensão da autonomia como princípio moral.

Enquanto propriedade da vontade, a autonomia é apresentada por Kant como a capacidade do ser racional de dar uma lei para si mesmo. Allison (1995, p. 94-95) retoma essa definição de autonomia como propriedade da vontade em seu contraste com a noção de heteronomia. Noutro sentido, para o comentador, Kant forneceria uma segunda definição de autonomia como propriedade da vontade no começo da terceira seção da Fundamentação, apresentada como liberdade positiva, em oposição à liberdade em sentido negativo. Segue-se ainda, na leitura da terceira seção, a identidade entre liberdade e ação moral quando Kant afirma que "uma vontade livre e uma vontade sob leis morais é uma e mesma coisa" (GMS, AA IV: 447; p. 349). É desse modo que, para Allison, é preciso derivar a concepção da autonomia como princípio moral enquanto propriedade da vontade. A identidade entre liberdade positiva e ação moral resulta em uma complicação que deve ser lembrada: se a ação livre só pode ser a ação moral, sendo qualquer outra ação uma ação sem liberdade, guiada por impulsos, então não seria possível uma deliberação entre os modos de ação. O agente racional não seria capaz de escolher uma ação, dado que a única ação livre seria a ação moral. É nesse sentindo, entende Allison, que alguns comentadores interpretaram a filosofia moral kantiana, exigindo para seu funcionamento uma concepção neutra de autonomia que pudesse fazer a mediação entre os dois modos de ação. Allison recusa essa leitura advertindo que ela foi incapaz de distinguir corretamente liberdade prática e autonomia, o que depende da análise da concepção kantiana de agente racional.

Sabe-se que a análise do agente racional da segunda seção da Fundamentação culmina no estabelecimento da autonomia como propriedade da vontade do agente. Para tanto,

Todavia, só por se apresentar racionalmente como dever, a representação da lei não garante que realizemos o dever a não ser que algo, este sim ligado à constituição física de maneira ostensiva, possa determinar-nos à sua realização. A representação da lei é o princípio objetivo de determinação da vontade pela razão; o princípio subjetivo é o respeito à lei. Daí a importância do conceito de máxima na filosofia moral kantiana. Apesar do caráter objetivo da lei, aquilo que é propriamente o fundamento da ação é o princípio subjetivo que conduz o sujeito para sua realização. A máxima é o princípio subjetivo que determina essa ação; contudo, a máxima não deve ser entendida simplesmente como uma adoção momentânea de determinado objetivo. Ela possui uma determinação universal (allgemein) da vontade tal que abarca não só um ou outro aspecto da vida do sujeito em questão, mas sim sua vida como um todo (cf. BITTNER, 2004, p. 7-25; ROHDEN, 2015, p. 581-582). A ação só será moral, justamente, quando o sujeito assumir a representação da lei como sua máxima, isto é, adotar princípio objetivo como seu princípio subjetivo. 
compreende-se que apenas uma vontade com a propriedade da autonomia é capaz de agir com base no imperativo categórico (Allison, 1995, p. 99). Para Allison, a explicitação kantiana da autonomia como propriedade da vontade, para se tornar princípio moral, requer que entendamos todas as teorias da ação moral como baseadas, de maneira exaustiva, na dicotomia entre autonomia, por um lado, e heteronomia, por outro. Quatro são os pontos fundamentais da análise de Allison (1995, p. 104): (i) a análise da moralidade com base no imperativo categórico mostra que se devem adotar máximas em virtude de sua forma legislativa e de sua universalidade, (ii) mas isso pressupõe uma capacidade de determinar a si mesmo a agir de maneira independente das inclinações; (iii) uma vontade com a propriedade da autonomia possui essa capacidade; (iv) assim, a moralidade baseada no imperativo categórico é possível se a vontade for autônoma. Apesar de sua coerência no contexto da Crítica da razão prática, essa corrente argumentativa é diferente na Fundamentação, algo importante para a compreensão do modo como Allison soluciona a ambiguidade do conceito de autonomia.

A Fundamentação, ao apresentar a fórmula da humanidade, ressalta a importância de se afastarem os móbiles (Triebfeder) sensíveis da vontade como característica essencial do imperativo categórico. Essa concepção exige, como sua condição de possibilidade, a autonomia como propriedade da vontade. Contudo, para Allison, ainda se faz necessária uma formulação do imperativo que torne explícita essa característica essencial; será assim que Kant apresentará o imperativo como autonomia, isto é, "a ideia da vontade de todo ser racional enquanto vontade universalmente legislante" (GMS, AA IV: 432; p. 253). Compreende-se, então, de que modo a exigência de se afastarem os impulsos sensíveis tornase a exigência de se expor o caráter autolegislante da vontade sob a forma do imperativo categórico. Para Allison, são exigências diferentes que nos levam, no interior da filosofia moral kantiana, às diversas significações da autonomia. A autonomia é propriedade da vontade (ainda que não se prove, mas seja apenas uma hipótese); caso contrário, o agente racional não poderia agir senão por impulsos. Mas enquanto propriedade da vontade ela fundamenta a própria possibilidade do imperativo categórico; caso contrário, sem a autonomia, sem a liberdade em sentido positivo, o imperativo categórico seria impossível. Por fim, seu surgimento como uma formulação do imperativo categórico atende à exigência de explicitar, em uma formulação, esse elemento que é uma característica essencial do imperativo categórico: afastar as inclinações da ação moral. Se nossa compreensão da posição dos comentadores está correta, eles partilham leituras relativamente 
próximas no que diz respeito à relação dos conceitos de imperativo categórico e autonomia da vontade. Carnois vê a autonomia como condição lógica do imperativo categórico; Allison compreende a autonomia como propriedade da vontade e como essa mesma condição.

As leituras dos dois comentadores se baseiam amplamente na compreensão das funções das diversas formulações do imperativo categórico entre si, das complicações e dos objetivos de cada uma delas. Marco Zingano, ao discutir a relação dessas formulações, apresentará um quadro de complicações cuidadosamente solucionadas por Kant no correr das páginas da Fundamentação enquanto funções das próprias formulações

Estas três formulações do imperativo categórico visam, mediante sua fricção, circunscrever o espaço de reflexão sobre o dever que a razão prática explora a partir de uma posição inicial do senso comum moral. No primeiro momento é enfatizado de universalidade, que a razão comum moral propõe, cuja forma é a mesma da lei natural. A lei moral aparece como se fosse lei natural, encobrindo exatamente o que a distingue dela, a saber, uma vontade que se quer racional e assim sai fora da natureza stricto sensu. Das duas uma: ou há uma implosão da lei moral dentro da lei natural, ou o natural mostra-se explodido para fora de si, tendo uma forma que aceita uma causalidade outra do que a razão teórica fundara. A segunda formulação alicerça a explosão do natural: aparece a humanidade como fim em si, portanto fora da série causal que inapelavelmente transforma todo fim em meio para outra coisa. Eis todo um jogo de fricção cujo objetivo é vislumbrar o princípio da autonomia e seu objeto, o reino dos fins, como horizonte em que se moviam. Mas esta última formulação retoma a ideia de um corpo que se prende à natureza através da noção de reino dos fins; porém, o natural é agora um domínio que permite um engendramento do humano, portanto um domínio que não somente é mas faz-se ser. Ora, assistimos ao aprofundamento de uma tensão; o ponto crítico será poder articular esses extremos em um único domínio. Sem essa recuperação do natural, embora até agora paradoxal, o agir moral não se explicitaria, mas fugiria para domínios incontroláveis pelo conceito, (ZINGANO, 1989, p. 63$64)^{9}$

O estabelecimento da lei moral como imperativo categórico recorre, necessariamente, ao afastamento das inclinações e exige, para sua realização, o afastamento da causalidade natural. Contudo, o processo de elaboração das formulações do imperativo categórico reafirma a aproximação entre o imperativo moral e essa causalidade que se buscou afastar. Apesar de esse processo aparentar uma introjeção equivocada da causalidade natural, ao

\footnotetext{
${ }^{9}$ Outro modo de compreender a relação entre as formulações, de maneira mais sintética, é-nos oferecido por Allison em seu livro sobre a Fundamentação. Para o comentador, há três exigências que Kant apresenta para a constituição do imperativo categórico: (i) forma universal, (ii) valor absoluto e (iii) comando incondicional. Ora, as formulações canônica e da lei da natureza atenderiam à exigência (i), a formulação da humanidade atenderia à exigência (ii) e, por fim, as formulações da autonomia e do reino dos fins atenderiam à exigência (iii) (ALLISON, 2011, p. 237). A nosso ver, as posições não são irreconciliáveis, mas tão somente abordam a questão de pontos de vista diferentes.
} 
contrário, devido à relação de analogia entre a fórmula canônica e a fórmula da natureza, nada temos além do desejo de aproximar o imperativo da intuição. Contudo, se nos atentarmos para a leitura proposta por Zingano, na qual temos um jogo de fricções na busca do princípio de autonomia, então a autonomia deve apresentar-se, necessariamente, como o elemento que se opõe à legislação natural: ela é pura e simplesmente a legislação da liberdade, e isso se torna tão mais claro quanto mais forçamos os limites do conhecimento racional moral comum, que se torna conhecimento filosófico. Nesse sentido, as interpretações serão tão mais pertinentes quanto mais clara for a concepção que o intérprete tem do conceito de autonomia da vontade.

É nesse ponto que a interpretação de Carnois parece problemática. A compreensão de autonomia de Bernard Carnois admite, em sua construção, uma concepção ampla de autonomia: toda vontade (ou razão prática) é autonomia em certo sentido, mesmo quando adota um princípio empiricamente condicionado como princípio subjetivo da ação. Assim, toda heteronomia implicaria uma autonomia, isto é, a capacidade do sujeito racional de escolher a heteronomia. Faz-se necessário, portanto, postular uma dupla concepção de autonomia: (i) a autonomia em sentido geral, submetida a contrários na escolha; e (ii) a autonomia moral. Para Carnois (1973, p. 118-119), a autonomia, na segunda acepção e para o ser racional finito, tanto constitui a lei moral quanto impõe sua obediência - isto é, a autonomia é o fundamento da lei $e$ o princípio da obrigação. A compreensão de autonomia de Carnois se desenha em contraste com as posições de Martin Heidegger e Gerhard Krüger. Martin Heidegger (1953, p. 215) interpreta a autonomia como um projeto da lei moral, ao passo que Gerhard Krüger (1961, p. 94) a interpreta, não como um projeto, mas sim como uma lei dada. Ainda, no que diz respeito à interpretação de Heidegger, é interessante notar um tom próprio deste autor. Para Heidegger, a razão prática se fundamenta sobre a imaginação transcendental e algo que seria sua espontaneidade juntamente à razão. Desse modo, a moralidade surge como manifestação da espontaneidade da razão prática no que diz respeito à determinação do sujeito enquanto tal. É nesse sentido que a autonomia acaba por se apresentar, não como uma lei dada, mas antes como um projeto. Carnois propõe o caminho intermediário: para ele, a lei moral não é uma lei inerente à natureza humana, mas sim à razão, sendo-lhe coextensiva, ou seja, ao mesmo tempo um projeto da lei moral e uma lei dada

A vontade autônoma é "a vontade pura", isto é, a vontade do ser racional enquanto racional, a vontade humana, enquanto considera-se sua essência puramente racional. A vontade autônoma não é outra que não a razão prática. A liberdade é a 
razão. A razão, que concebe a liberdade, se reconhece nela: o conceito de liberdade é o espelho da razão. (Carnois, 1973, p. 120-121)

O conceito de liberdade reaparece constantemente nessas considerações e, mais fortemente, quando queremos entender a relação dos conceitos de autonomia e imperativo categórico. Kant afirma que "a autonomia é a qualidade da vontade pela qual ela é uma lei para si mesma" e que "o princípio da autonomia é, portanto: não escolher de outro modo senão de tal modo que as máximas de sua vontade também estejam compreendidas ao mesmo tempo como lei universal no mesmo querer" (GMS, AA IV: 440; p. 285). A terceira seção da Fundamentação inicia com a afirmação de que

A vontade é uma espécie de causalidade de seres vivos na medida em que são racionais, e a liberdade seria aquela propriedade dessa causalidade na medida em que esta pode ser eficiente independentemente da determinação por causas alheias; assim como a necessidade natural [é] a propriedade da causalidade de todos os seres irracionais de ser determinada à atividade pela influência de causas alheias. (GMS, AA IV: 446; p. 347)

Da distinção entre dois modos de causalidade segue a apresentação de duas legislações distintas, uma própria à natureza, e outra própria à liberdade. Não obstante, há na fillosofia kantiana uma ampla concepção de liberdade. Na Crítica da razão pura define-se aquilo que é prático como "tudo aquilo que é possível pela liberdade" (A 800/B 828). Contudo, a principal concepção de liberdade na primeira Crítica é somente a liberdade em sentido cosmológico ou transcendental, isto é, a capacidade de iniciar absolutamente uma cadeia causal (A 448/B 476). Na Fundamentação apresentam-se outras duas concepções de liberdade: a liberdade em sentido negativo e a liberdade em sentido positivo. A liberdade em sentido negativo é, como citado, a capacidade de ação eficiente sem a determinação de causas alheias. Porém, segundo Kant, essa definição é imprópria para determinar a essência da liberdade; faz-se necessária uma concepção positiva da mesma

Visto que o conceito de uma causalidade traz consigo o de leis, segundo as quais por algo, que chamamos de causa, tem de ser posto algo de outro, a saber, a consequência, então a liberdade, embora não seja uma propriedade da vontade segundo leis naturais, nem por isso é de todo sem lei, mas, antes pelo contrário, tem de ser uma causalidade segundo leis imutáveis, porém de espécie particular; pois, de outro modo, uma vontade livre seria uma coisa absurda [...] o que pode ser, então, a liberdade da vontade senão autonomia, isto é, a propriedade da vontade de ser para si mesma uma lei? (GMS, AA IV: 445-447; p. 347-349) 
Ora, a concepção de liberdade como apresentamos não é, contudo, dupla. Tanto a definição em sentido negativo quanto em sentido positivo dizem respeito à mesma noção de liberdade; todavia, apenas a definição de liberdade em sentido positivo expressa, segundo Kant, a essência da liberdade: propriedade da vontade de ser para si mesma uma lei. Autonomia e liberdade da vontade são, assim, idênticos. O núcleo conceitual da autonomia da vontade é a noção de autolegislação, e a autolegislação é, também, idêntica à definição positiva de liberdade. E, se a liberdade em sentido positivo é a capacidade da vontade de dar a lei para si mesma, e se dar a lei para si mesma é autonomia, então o agir livre é seguir o imperativo categórico. Podemos, assim, reler sob nova perspectiva a passagem já citada da Fundamentação: "Portanto, uma vontade livre e uma vontade sob leis morais é uma e a mesma coisa" (GMS, AA IV: 447; p. 349).

Bernard Carnois defende uma leitura extensiva, como observamos, desses conceitos. Sua dificuldade, no entanto, é defender uma concepção de autonomia não moral, isto é, uma capacidade de deliberação entre tendências que não teria qualquer valor moral. Essa concepção neutra de autonomia é útil ao comentador para distinguir a autonomia em sentido kantiano; entretanto, ela não possui amparo textual algum: Kant nunca afirma, até onde sabemos, qualquer tipo de autonomia nesse sentido. Há um evidente problema: faz-se necessário postular algum tipo de autonomia prévio às ações em geral, sejam morais, sejam não morais, e que garanta ao sujeito seja o cálculo de meios para fins, seja a ação moral propriamente dita. A nosso ver, esse problema se coloca por uma confusão entre uma teoria da ação humana e uma teoria dos modos de deliberação. Há deliberação (não em sentido político, necessariamente) quando um sujeito precisa decidir os melhores meios para realizar determinado fim, e também há deliberação no interior dos atos morais. Por exemplo, faz parte da lei moral ajudar aqueles que precisam de ajuda - mas quais são os modos de ajudar? Existe, por parte do agente, um processo deliberativo para decidir os tipos de ações que realizam aquilo que é próprio da moralidade. Pode-se, evidentemente, chamar essa propriedade deliberativa de autonomia em sentido neutro; contudo, corre-se o risco de confundir e se deixar diluir a concepção kantiana de autonomia: é o que acontece com as concepções que chamamos psicológicas.

Ainda assim, compreender a autonomia como essência do imperativo categórico é compreender a liberdade em sentido positivo como tendo essa mesma função. As leituras dos comentadores não diferem no que diz respeito à solução do problema: há uma dupla consideração das primazias, e uma confusão dos textos da Fundamentação, 
por uma dupla exigência que a investigação tenta alcançar. E, no que diz respeito à relação entre imperativo categórico e autonomia da vontade, não há conflito algum, seja no que se refere à primazia na ação moral, seja na constituição da filosofia prática. Ao contrário, um conceito opera a elucidação do outro e ambos apontam, em seus interiores, para o que parece ser o verdadeiro núcleo da filosofia moral kantiana: a ideia de liberdade.

\section{A IDEIA DE LIBERDADE E O PROBLEMA DA DEDUÇÃO DA FUNDAMENTAÇÃO}

A segunda parte deste artigo busca expor, em linhas gerais, as dificuldades que seguem a interpretação da Fundamentação e como elas se conectam com a discussão anterior, fundando-se no conceito de liberdade positiva. A autonomia é propriedade da vontade na medida em que, como liberdade, é exigida para que se possa pensar a possibilidade da ação moral. Ela também será princípio moral na medida em que, como capacidade do ente racional de dar a si mesmo sua lei, legisla, como imperativo categórico, uma lei universal e necessária, figurando tanto como condição de possibilidade do imperativo categórico quanto como uma de suas formulações. A centralidade da ideia de liberdade, como pudemos observar, é o que garante a coerência interna desses conceitos na filosofia moral kantiana. Apenas quando admitimos uma vontade livre os problemas que se ligam à moralidade das ações podem ser postos. Sabe-se que o Prefácio da Fundamentação apresenta um duplo objetivo com um duplo método para a investigação: (i) buscar e estabelecer o princípio supremo da moralidade (ii) mediante um método que tem um momento analítico e um momento sintético. As duas primeiras seções da obra tratam, justamente, da busca do princípio supremo da moralidade, e a terceira seção, por seu turno, é reservada tão somente para seu estabelecimento. É por essa razão que, em diversos momentos da exposição, Kant reforça o caráter eminentemente hipotético da investigação: apesar da validade de todos os resultados obtidos, essa investigação admitiu como hipótese que há, de fato, ações dotadas de valor moral, sem contudo garantir a validade dessa hipótese. Nas páginas que se seguem, gostaríamos de delimitar os problemas relevantes, no que diz respeito a nosso artigo, para se compreender a relação entre imperativo categórico e autonomia da vontade, bem como demonstrar os problemas de interpretação que esse texto suscita entre os comentadores. 
Na Fundamentação consta que, se admitirmos a liberdade da vontade, segue-se por análise desse conceito a moralidade e seu princípio; no entanto, o princípio da moralidade é uma proposição sintética a priori ${ }^{10}$

Uma vontade absolutamente boa é aquela cuja máxima pode sempre conter a si mesma, considerada como lei universal, dentro de si; com efeito, por análise do conceito de uma vontade absolutamente boa, essa propriedade da máxima não pode ser encontrada. Tais proposições sintéticas, porém, só são possíveis pelo fato de que ambas as cognições podem ser ligadas entre si mediante a conexão com uma terceira (GMS, AA IV: 447; p. 349-351).

O terceiro termo, para conectar as duas cognições, será o conceito positivo de liberdade. Assim, faz-se necessária a "dedução do conceito da liberdade a partir da razão prática pura (e, com ela, a possibilidade de um imperativo categórico)" (GMS, AA IV: 447; p. 351). ${ }^{11}$ Essa liberdade que precisa ser deduzida deve ser admitida não apenas aos seres racionais finitos, mas à vontade de todo ser racional em geral, porque a derivação da moralidade se prende à noção de uma vontade em geral. Assim, a dedução do conceito de liberdade precisa prová-la como propriedade da vontade de todo ser racional. Nesse sentido, Kant afirma que "todo ser que não pode agir senão sob a ideia da liberdade é, por isso mesmo, de um ponto de vista prático, realmente livre" (GMS, AA IV: 448; p. 353), algo que, segundo Kant, deve ser considerado válido também para a filosofia teórica. Admitir a liberdade como propriedade da vontade de todo ser racional apenas prova que, dada a ideia de liberdade, seguem a lei moral e o imperativo categórico; isso não prova, contudo, a noção de liberdade e, mais especialmente, a liberdade como propriedade da vontade do ser racional finito. O primeiro risco que o filósofo afasta é o de argumento circular: provar, supondo a

${ }^{10} \mathrm{O}$ paralelo entre a Fundamentação e os Prolegômenos é explicitado nessa exigência. A resposta para a pergunta de como são possíveis juízos sintéticos a priori retoma, na terceira seção, uma tópica que é própria da primeira Crítica, mas apenas no que diz respeito ao campo teórico. Entretanto, até esse momento da obra, admitiu-se a possibilidade do princípio e se desmembrou sua constituição por mera análise, como operado nos Prolegômenos. Se seguirmos as indicações da primeira Crítica (A 9-10/B 13-14), teremos que um juízo sintético a priori conecta um sujeito a um predicado, predicado este que não está contido no conceito do sujeito e cuja ligação é a priori, ou seja, sem amparo na experiência empírica. Para comentadores como Wolff (1971, p. 209), Wood e Schönecker (2015, p. 175), essa questão parece se converter, no campo prático, na questão "como é possível o imperativo categórico?".

${ }^{11}$ Como se sabe, a alegoria jurídica que funda a noção de dedução transcendental é apresentada na Crítica da razão pura e baseia-se na distinção entre questão de fato (quid facti) e questão de direito (quid juris). Dieter Heinrich (1994, p. 29-45) argumenta que, para a devida compreensão da noção de dedução, devemos dar um peso singular para a noção jurídica nela contida: a dedução visa a legitimar o uso a priori dos conceitos puros do entendimento. Na Fundamentação, podemos pensar de maneira análoga a argumentação; todavia, o que se busca legitimar é a aplicação da liberdade no caso do ente racional finito. É o duplo ponto de vista que garante essa aplicação e, desse modo, legitima o uso da liberdade. Marco Zingano (1989, p. 101-102), apesar de defender a dedução como sendo dedução da autonomia da vontade, argumenta que a dupla função da Fundamentação busca e estabelecimento - pode ser entendida como os dois procedimentos que, em outras obras, são chamados de dedução metafísica e dedução transcendental. 
liberdade, a ideia de moralidade e, em seguida, com a ideia de moralidade, tentar provar a liberdade da vontade. ${ }^{12}$

Para escapar desse problema, isto é, para provar de maneira válida a liberdade e, por extensão, a moralidade em uma vontade finita, o filósofo desenvolve um argumento que dependerá da distinção entre fenômeno (Erscheinung) e coisa em si. Todas as representações que não são fruto de nosso arbítrio são fruto da maneira como somos afetados, mas deve-se considerar que só conhecemos pelo entendimento os objetos enquanto fenômenos. Também se devem supor, por trás dos fenômenos, coisas em si mesmas. Segue-se dessa distinção uma outra, entre mundo sensivel (Sinnenwelt) e mundo inteligível (Verstandeswelt). ${ }^{13}$ Deve-se

12 Esse trecho da obra é amplamente conhecido na literatura como argumento da suspeita de círculo. Para Bernard Carnois (1973, p. 88-89), tal problema inaugura o método sintético na moralidade kantiana, método que é retomado na Crítica da razão prática. O método consiste em conectar duas noções que não estão ligadas analiticamente, a saber, as noções de vontade finita e moralidade. Essa conexão depende de que se estabeleça a reciprocidade entre liberdade e legislação moral, por um lado, e a liberdade como propriedade da vontade de todo ser racional enquanto racional, por outro lado. A suspeita de círculo tornaria esse procedimento falacioso na medida em que, supondo a liberdade como propriedade da vontade, dela derivaria a moralidade e, tendo a moralidade, seria posta a liberdade como necessariamente atrelada a ela. Assim, a falsidade estaria em dois níveis: (i) quando se ligam liberdade e vontade finita; e (ii) quando se usam moralidade e liberdade como fundamentos recíprocos de prova. Wood e Schönecker (2014, p. 200-204) apontam para elementos semelhantes. Segundo os comentadores, Kant precisa conciliar duas posições teóricas nesse texto: (i) o estabelecimento do ser humano como livre; e (ii) a relação de analiticidade entre liberdade e moralidade. Nesse ponto, a tese desses comentadores não se distancia substancialmente da posição de Allison (1995, p. 202-211). Para que a moralidade possa ser estabelecida, é necessário que sejam dadas as condições da liberdade do ente racional finito. Este, por si mesmo, não pode ser dito livre em sentido estrito, já que sua vontade é constantemente afetada pelas inclinações, mas ser livre é condição para que a moralidade possa ser para ele possível. Se Kant acaso utilizar como prova da liberdade a moralidade, cujo fundamento é a própria liberdade, o argumento se torna circular e, desse modo, inválido.

13 A introdução da distinção entre coisas consideradas enquanto fenômenos e enquanto coisas em si mesmas marca, a nosso ver, a introdução do elemento propriamente transcendental no interior da argumentação da Fundamentação. Até esse momento, a Fundamentação se desenvolveu sob a figura das passagens do conhecimento racional moral comum para o conhecimento filosófico e da filosofia moral popular para a metafísica dos costumes. Agora, na terceira seção, temos a introdução da figura da crítica da razão pura prática, ou seja, os aspectos inerentes ao modo de argumento que já estavam presentes na primeira Crítica. Com isso não queremos dizer que o restante da obra não possua uma argumentação inerente e própria ao kantismo, mas que, no que diz respeito à crítica da razão, a introdução dessa distinção marca decisivamente a conexão da Fundamentação com a Crítica da razão pura. R. P. Wolff (1973, p. 203) nos recorda que a introdução da distinção entre coisas em si e fenômenos fundamenta a distinção que nos permitirá escapar da suspeita de círculo: a distinção entre mundo sensível e mundo inteligível (ou do entendimento). Para tanto, sugere que retomemos a Crítica da razão pura, em especial a Terceira Antinomia, para lá buscarmos os fundamentos críticos dessa distinção. Bernard Carnois (1973, p. 19-33) e Henry Allison (1995, p. 14-27) chamam atenção para um fato curioso: o problema da liberdade, na Crítica da razão pura, não se coloca no nível da psicologia enquanto propriedade dos agentes, mas no nível da cosmologia, campo das legislações possíveis no interior do mundo. Ora, a Terceira Antinomia é solucionada, justamente, pela admissão de uma dupla consideração do mundo: enquanto consideração fenomênica não há liberdade, mas tudo é regido segundo as leis da natureza; enquanto consideração noumênica, a liberdade em sentido transcendental pode ser pensada como um conceito não contraditório. Assim, observam os comentadores, Kant cria o espaço lógico do conceito de liberdade, advogando a necessidade de que o conceito de liberdade prática se fundamente no conceito de liberdade transcendental. Desse modo, construímos o campo lógico do conceito que, por mais que não possa ser objeto de uma prova aos moldes das ciências empíricas, recebe mediante o procedimento da Dialética Transcendental uma significação precisa. Será a partir dessa base lógica que a Fundamentação poderá pensar o conceito de liberdade prática em uma dupla visão: enquanto liberdade negativa e enquanto liberdade positiva. A primeira, apenas come 
considerar o ser racional finito, devido à sua própria autoatividade racional, como pertencente a ambos os mundos - tanto ao mundo sensível quanto ao mundo inteligível

\begin{abstract}
Enquanto inteligência [...], um ser racional tem de se ver não como pertencendo ao mundo sensível, mas ao mundo inteligível; por conseguinte, ele tem dois pontos de vista [...] primeiro, na medida em que pertence ao mundo sensível, sob leis da natureza (heteronomia), segundo, enquanto pertencente ao mundo inteligível, sob leis que, independentes da natureza, sejam, não empíricas, mas fundadas na razão apenas [...]. Enquanto ser racional, logo pertencente ao mundo inteligível, o homem jamais pode pensar a causalidade de sua própria vontade de outro modo senão sob a ideia da liberdade; pois independência de causas determinadas do mundo sensível (tal como a razão tem de se conferir sempre) é a liberdade. Ora, à ideia da liberdade está inseparavelmente ligado o conceito da autonomia, a este, porém, o princípio universal da moralidade, o qual subjaz, na ideia, a todas as ações de seres racionais, do mesmo modo que a lei natural a todas as aparências [...]. E, assim, os imperativos categóricos são possíveis porquanto a ideia da liberdade faz de mim um membro de um mundo inteligível, donde resulta que, se eu fosse isso apenas, todas as minhas ações seriam sempre conformes à autonomia da vontade, mas, visto que eu me vejo ao mesmo tempo como membro do mundo sensível, devem ser conformes [à autonomia] (GMS, AA IV: 452-454; p. 369-375).
\end{abstract}

Essa apresentação da estrutura do texto da Fundamentação, por si só, deixa transparecer o amplo conjunto de dificuldades que os comentadores observaram, chegando a conclusões dispares acerca de como interpretar essa última passagem. As primeiras dificuldades são de ordem textual. Sabe-se que a terceira seção se caracteriza como uma passagem "da Metafísica dos Costumes para a Crítica da Razão Pura Prática”. Essa passagem parece ser caracterizada como a operação da dedução. Porém, há momentos em que o filósofo se refere à dedução como sendo uma dedução da liberdade, e há momentos em que a chama de dedução do imperativo categórico. Do mesmo modo, qual dos passos da argumentação deve ser entendido como constituindo, propriamente, a dedução? Esse argumento pode ser tanto a introdução da distinção entre mundo sensível e mundo inteligível (mais provável) quanto a admissão da liberdade como propriedade da vontade de todo ser racional (menos provável). Do mesmo modo, qual deve ser o estatuto filosófico dessa dedução? Ela parece integrar a passagem à crítica da razão na Fundamentação; contudo, houve comentadores que defenderam uma falência argumentativa, por parte do filósofo, no que diz respeito ao conteúdo dessa seção (Almeida, 1999, p. 57-84).

não coerção externa; a segunda, como autonomia, capacidade de dar para si mesmo sua lei. É essa autonomia que carrega a noção de legislação ao campo prático. 
R. P. Wolff (1989, p. 191-194), em seu comentário sobre a Fundamentação, dedica pouquíssima atenção ao conteúdo da terceira seção, preferindo fazer apenas uma exposição geral do argumento, consciente das dificuldades que envolvem uma interpretação ampla. H. J. Paton (1971, p. 199) também interpreta a terceira seção de maneira rápida, valendo mencionar sua compreensão desta como dedução transcendental do conceito de autonomia, essência do imperativo categórico. Dieter Schönecker e Allen Wood (2014, p. 179-180) interpretaram a dedução da terceira seção da Fundamentação como sendo a dedução, não da liberdade, mas do próprio imperativo categórico. Admitindo com ressalvas a tese da analiticidade como ponto de partida da terceira seção, os comentadores entendem que a resposta à pergunta “como é possível o imperativo categórico?” é a própria função daquilo que Kant chama de "dedução" no interior dessa seção. Assim, a grande função dessa seção seria demonstrar a validade do imperativo categórico. O principal passo de tal dedução é considerar o ser racional como participante de um mundo inteligível e, considerando sua própria vontade como uma causalidade eficiente diferente da causalidade natural, segue-se da liberdade a moralidade e, finalmente, a autonomia. O centro da leitura desses comentadores está na concepção de um princípio ontológico-ético que precisaria conduzir a concepção moral kantiana: a consciência do homem de ser racional, portanto membro de um mundo inteligível e, desse modo, sujeito às leis que daí decorrem. No que diz respeito à liberdade, eles entendem o argumento da liberdade enquanto pertencente a todo ser racional como uma dedução da liberdade, mas em um sentido fraco. Vale ressaltar que Wood e Schönecker (2014, p. 179-207) parecem considerar os argumentos dessa seção, e mesmo a dedução do imperativo categórico, argumentos fracos: a introdução dos dois mundos não se encaixa nas concepções epistemológicas da primeira Crítica, não dando sustentação devida a essas teses. Henry Allison (1995, p. 214-233) compreende essa dedução como sendo a dedução da própria lei moral, possuindo como uma de suas premissas aquilo que chama de tese da reciprocidade, que seria expressa por Kant ao afirmar que "uma vontade livre e uma vontade sob leis morais é uma e a mesma coisa" (GMS, AA IV: 447; p. 349). Para Allison, há uma distinção entre essa dedução da lei e certa dedução própria ao imperativo categórico, bem como uma falha no processo argumentativo que obrigaria Kant a operar uma revisão de seu argumento de legitimação da moralidade na Crítica da razão prática. Retomando novamente a leitura de Dieter Schönecker e Allen Wood (2015, p. 175-189), ao defenderem a dedução da Fundamentação, não como dedução da lei moral em geral, mas como dedução do imperativo categórico especificamente, os comentadores recusam uma leitura 
segundo uma tese da reciprocidade, defendendo antes uma tese da analiticidade, comum entre comentadores recentes, que se apoia em passagens nas quais Kant afirma que, "se a liberdade da vontade é pressuposta, daí se segue, por mera análise de seu conceito, a moralidade juntamente com seu princípio" (GMS, AA IV: 447; p. 349). ${ }^{14}$ Por fim, Marco Zingano (1898, p. 102) compreende a dedução como dedução transcendental da autonomia da vontade, baseando-se na noção de espontaneidade.

Segundo defendemos, a concepção de liberdade em sentido positivo funciona como base para o conceito de autonomia, e esse, por sua vez, é a essência do próprio imperativo categórico: a compreensão da concepção moral kantiana passa pelo entendimento de como essa última seção opera a defesa tanto do conceito de liberdade quanto do conceito de autonomia da vontade. Mesmo que haja coerência argumentativa entre as duas primeiras seções, que cumprem a busca do princípio supremo da moralidade, sem seu estabelecimento a filosofia moral kantiana perde consistência, tornando-se apenas um delírio da razão, e a obra não cumpre seu objetivo principal: fundamentar a moralidade. Além disso, compreender o que a dedução, de fato, pretende legitimar também coloca em questão a própria continuidade das considerações kantianas acerca da filosofia prática. Se, de fato, a dedução é a dedução do imperativo categórico, então, na Crítica da razão prática, encontramos uma nítida rejeição dessa possibilidade: nessa última obra, Kant estaria se corrigindo após uma falência argumentativa ao recusar qualquer possibilidade de dedução do princípio supremo da moralidade. Entretanto, Kant admite a Fundamentação como necessária, em certa medida, para a Crítica da razão prática ${ }^{15}$ Desse modo, compreender a dedução da terceira seção não

\footnotetext{
${ }^{14}$ No que diz respeito às interpretações ligadas às noções de reciprocidade e analiticidade, especialmente representadas pelas leituras de Henry Allison, Allen Wood e Dieter Schönecker, a nosso ver elas não se afastam de maneira substancial. De fato, ao afirmarmos a reciprocidade entre moralidade e liberdade, focamos uma ligação entre ambas que não se vale de uma noção forte de qualquer uma, o que é diferente de quando dizemos que da ideia de liberdade segue, analiticamente, a ideia de moralidade nela contida enquanto sua legislação própria, ou seja, autonomia. Contudo, no caso do ente humano, dizer que a moralidade se dá sob a forma da reciprocidade nos parece menos acertado, uma vez que dependemos do estabelecimento da possibilidade da liberdade para dela, por análise (igual ao ser racional absolutamente livre), derivarmos a moralidade.

${ }^{15} \mathrm{Na}$ Crítica da razão prática, há uma indicação importante que pode, em certo sentido, contribuir para a interpretação que propomos. A relação entre liberdade e lei moral é apresentada nesse texto segundo uma relação distinta daquela da Fundamentação. A liberdade é apresentada (KpV, AA V: 4n; p. 17n) como a ratio essendi, ou seja, a razão de ser da lei moral, na qual ela encontra sua fonte; já a lei moral é dita ratio cognoscendi da liberdade, ou seja, o meio pelo qual eu conheço que sou, de fato, livre. Uma investigação sobre o conhecimento da liberdade em nós é diferente de uma investigação sobre a moralidade, sua origem e condições de possibilidade - em suma, sua fundamentação. Se esse é o caso, a distinção apresentada na Crítica da razão prática recoloca uma relação que, na Fundamentação, parece turva. Kant, em diversas passagens, aproxima uma diversidade de noções de maneira curiosa, seja aproximando liberdade e lei moral (tanto como legislação quanto como autonomia), seja a identidade entre vontade e razão, ou, ainda, entre liberdade e razão prática. A distinção entre agir segundo a liberdade e agir segundo a lei moral parece-nos ser apenas uma distinção de razão. Se há de fato reciprocidade entre legislação moral e liberdade no conceito de autonomia, é porque ambas são, de algurn
} 
só conduz à conclusão do projeto da Fundamentação, mas conduz também nossa compreensão da continuidade da filosofia moral em marcos críticos.

\section{CONSIDERAÇÕES FINAIS}

Nosso texto buscou compreender a relação entre imperativo categórico e autonomia da vontade na Fundamentação. Defendemos a unidade conceitual do imperativo categórico e da autonomia da vontade, com uma primazia que varia segundo o ponto de vista analisado, operando apenas uma pequena variação, no que diz respeito ao conceito de autonomia, na leitura proposta por Carnois. Também defendemos, seguindo a leitura de Allison, que a autonomia pode ser tanto uma formulação do imperativo categórico quanto uma propriedade da vontade sem que isso acarrete problemas conceituais. O ponto de desenlace da questão é considerar a autonomia como liberdade em sentido positivo, conceito fundamental para compreendermos o próprio conceito de autonomia. Ser livre é condição para que se possa, legitimamente, julgar acerca do certo e errado em sentido moral. Dessa maneira, as considerações sobre a liberdade e sua legitimidade são a continuação natural dessa investigação, não só tendo em vista a continuidade textual da Fundamentação, mas também sua exposição conceitual e os problemas levantados que a ensejam. Como observou Henry Allison, a filosofia kantiana é, em grande medida, uma filosofia da liberdade. Compreender o papel da liberdade na Fundamentação, isto é, a legitimidade desse conceito, é compreender a peça final do projeto da obra.

modo, autonomia - e mesmo a distinção entre autonomia, liberdade e legislação se mostra também, no fundo, uma distinção de razão. 


\section{REFERÊNCIAS BIBLIOGRÁFICAS}

ALLISON, H. Kant's Groundwork of the Metaphysics of Morals. Oxford: Oxford University Press, 2011.

. E. Kant's Theory of Freedom. Cambridge: Cambridge University Press, 1995.

ALMEIDA, G. A. Crítica, Dedução, Facto da Razão. In: Analytica, Rio de Janeiro, v. 4, n. 1, 1999.

. Introdução. In: KANT, I. Fundamentação da metafísica dos costumes. São Paulo: Discurso Editorial, 2009. p. 11-57.

BECK, L. W. A Commentary on Kant's Critique of Practical Reason. Chicago: Chicago University Press, 1960.

BITTNER, R. Máximas. Trad. de M. L. Engelman e R. P. Severo. In: Studia Kantiana, n. 5, 2004. p. 7-25.

CARNOIS, B. La cohérence de la doctrine kantienne de la liberté. Paris: Seuil, 1973.

HEIDEGGER, M. Kant et le problème de la métaphysique. Paris: Gallimard, 1954.

HENRICH, D. Kant's Notion of a Deduction and the Methodological Background of the First Critique. In: FÖRSTER, E. (ed.). Kant's Transcendental Deduction. Stanford: Stanford University Press, 2989. p. 29-45.

HILL, T. E. Jr. Dignity of Practical Reason in Kant's Ethical Theory. Ithaca: Cornell University Press, 1992.

KANT, I. Crítica da razão prática. Trad. M. Hulshof. Petrópolis: Editora Vozes, 2016.

. Crítica da razão pura. Lisboa: Fundação Calouste Gulbenkian, 2013.

. Fundamentação da metafísica dos costumes. Trad. G. A. Almeida. São Paulo: Barcarolla e Discurso Editorial, 2009.

. Gesammelte Schriften: herausgegeben von der Deutschen Akademie der Wissenschaften. Berlim: Walter de Gruyter, 1902.

. Prolegômenos a toda metafísica futura. Trad. A. Morão. Lisboa: Edições 70, 2015.

KRÜGER, G. Critique et morale chez Kant. Paris: Beauchesne, 1960.

PATON, H. J. The Categorical Imperative: A Study in Kant's Moral Philosophy. Filadélfia: University of Pennsylvania Press, 1971. 
ROHDEN, V. Notas complementares. In: KANT, I. Crítica da razão prática. São Paulo: Martins Fontes, 2015. p. 581-582.

SCHNEEWIND, J. B. A invenção da autonomia: uma história da filosofia moral moderna. Trad. de M. F. Lopes. São Leopoldo: Editora UNISINOS, 2001.

SCHÖNECKER, D.; WOOD, A. Kant's Groundwork for the Metaphysics of Morals: A Commentary. Cambridge, MA: Harvard University Press, 2014.

SUllivanS, R. J. Immanuel Kant's Moral Theory. Cambridge: Cambridge University Press, 2000.

WOLFF, R. P. The Autonomy of Reason: A Commentary on Kant's Groundwork of the Metaphysics of Morals. Londres: Harper Publishers, 1986.

ZINGANO, M. Razão e história em Kant. São Paulo: Brasiliense, 1988. 